\title{
XXV. Report made to the institute on two memoirs of M. Gratien Lepere, engineer of the imperial roads and bridges, on natural and artificial puzzolano
}

\section{Chaptal}

To cite this article: M. Chaptal (1809) XXV. Report made to the institute on two memoirs of M. Gratien Lepere, engineer of the imperial roads and bridges, on natural and artificial puzzolano, Philosophical Magazine Series 1, 34:137, 178-181, DOI: 10.1080/14786440908562945

To link to this article: http://dx.doi.org/10.1080/14786440908562945

$$
\text { 曲 Published online: } 18 \text { May } 2009 .
$$

Submit your article to this journal $₫$

\section{凹 Article views: 2}




\section{[ 178 ]}

XXV. Report made to the Institute on two Memoirs of M. Gratien Lepere, Engineer of the Imperial Roads and Bridges, on natural and artificial Puzzolano. By M. Chaptal *

E puzzolano is applied in buildings under water. The property possessed by this volcanic substance of speedily becoming hard when mixed with sour lime, in the composition of cements for hydraulic purposes, has rendered it a most important article; but the difficulty of procuring it from Italy while the navigation of the seas is interrupted, has made it extremely scarce and dear. Attempts have therefore frequently been made to procure a substitute for puzzolano, in substances which are to be procured in all countries and at a low price.

It seems, therefore, an interesting subject to collect the various processes which have been employed for adapting diffuent mineral substances to the uses of puzzolano, and with this view I have drawn up the present extract of M. Lepere's two memoirs. without binding myself to follow his order.

A substitute for puzzolano may be procured in three ways. 1st, By employing the remains of the extinguished volcanoes which almost all countries produce. $2 \mathrm{dly}$, By substituting some other volcanic products for puzzolano. $3 \mathrm{dly}$, By giving to certain mineral substances, by calcination, all the properties of these volcanic productions,

Messrs. Desmarets and Faujas St. Fond long ago made known some strata of good puzzolano in the volcanoes of Auvergne and Vivarais. I also pointed out this substance in the volcanoes which separate Lodeve from Bedarieux, in the department of the Herault, and it has been employed with success in the construction of bridges and other hydraulic buildings.

We may also find a substitute for puzzolano in other volcanic products, such as basalt, pumice stones carefully pounded, \&c.

In $1737 \mathrm{M}$. Guyton de Morveau sent to M. de Cessart, at Cherbourg, some calcined basalts from the extinguished volcano of Drevin, in the department of the Var and Loire. The latter proved by conclusive experiments, that they might be employed with great advantage in buildings under water.

The Dutch terrass is a kind of pumice stone brought

* From Annales de Chimie, tome lxiv. p. 273.

from 
from Bonn and Andernach. At Dordrecht, at the mouths of the Rhine and Meuse, the operation of pounding is effected.

But these resources are local; ind as the manufacture of puzzolano may become general, we proceed to describe the best means of attaining it.

It would be difficult to assign the period at which pounded bricks and the earthy residue from the distillation of aquafortis were substituted for volcanic puzzolano. Their use, however, has become general, particularly where there are no sea-ports in the vicinity at which real puzzolano can be furnished: even in the South of France they prefer the earthy residue of the distillation of aquafortis to the best puzzolanos for coating the inside of the wine tubs, which are almost all of mason, work, and for the ccments used by individuals in hydraulic works. The earth employed in the South of France for the decomposition of saltpetre, by extracting the aquafortis from it, is an cchrey earth very much charged with iron, and more or less reddened by the oxide of this metal. When it is wanted for cement, it is only necessary to beat it up with lime and a proper quantity of water. M. Lepere relates some experiments made at Paris by the engineers of roads and bridges, from which it appears that an immersion of eight days was sufficient for aquafortis cements to acyuire a hardness fit to resist a billet of wood when forced against it with the whole strength of a man; whereas the Italian puzzolano required six weeks before it attained the same degree of harduess.

In general the quality of the earth is better in proportion as it is charged with iron.

This last observation is equally applicable to pounded bricks : in general they do not make a good cement unless they are well burnt, and made of verv ferruginous earth.

Twenty years ago I suggested the above substitutes for puzzolano; and the result of my comparative trials made in the port of Cette, under the inspection of the engineers of the province of Languedoc, was published in 1787 , in a memoir printed by Didot, by order of the states-general of the province.

The means which I suggested for making this artificial puzzolano are simple, and may be put in practice almost cvery where. Balls should be made of the ochrey earth, and burned in a lime or potter's kiln. In order to form these balls, the earth must be moistened with a sufficient quantity of water; and when the balls are made, they should be burned until they pass from a red to 2 black colour, and M 2 the 
the angles of the scales formed when they are broken exhibit sharp and shining edges.

In the same work I proposed to substitute the blackish schists which are decomposed in the air for puzzolanos, Those which are in cakes are best; but in all cases they must be strongly calcined, in order to give them the requisite properties.

M. Lepere relates that M. Vitalis, professor of chemistry and secretary to the Rouen Academy, and M. Lamassen, chief engineer of the department of the Lower Seine, have made most excellent puzzolano hy the calcination of some ochrey earths in the environs of Rouen: this was effected by burning the earth in a conmon furnace with alternate strata of common charcoal. This puzzolano was subjected to some trials on a large scale, and it was composed in the following manner :

One part and a half of yellow calcined ochrey earth.

One part and three-fourths of well washed siliceous sand.

One part and an eighth of sour lime.

Two parts of chips from calcareous stone and silex.

From these and seceral other experiments (the proportions of which were varicd) it results, that the artificial puzzolano constantly exhibited the same effects as the best puzzolano of Italy. M. Lepere was an eye-witness of all these comparative experiments.

There can be no doubt, therefore, that wherever there are ochrey earths, artificial puzzolano may be made with great facility.

What is called Dutch terrass is in many respects similar to the artificial puzzolano in question.

The ashes, or rather scorix, left when coals are burnt, may atso be applied to the same purpose. M. Guyton caused a trial to be made at Cherbourg, and it succeeded well.

M. Gratien Lepere, having been intrusted in 1804 with constructing the foundation of the new arsenal at Cherbourg, began to turn his attention to the best method of supplying the puzzolano of Italy. He knew that the Swedes had already used a very hard black slate with this view, after being twice strongly calcined in a lime-kiln.

M. Lepere thought he perceived a great analogy between the Swedish stone and the rocks of Cherbourg, particularly those of port Bonaparte, which, when dug into, exhibited a black schistus, hard, ferruginous, and falling off in scałes 
of various thickness: subsequent experiments, however, proved that the slaty schistus of Roule, in the environs of Cherbourg, is preferable, and that good mortar. may be made with the ferruginous schist of Haineville, which is inferior, bowever, to the two former.

After having multiplied and varied his experiments in such a manner as to present positive results, M. Lcpere, in conjunction with the committee of engineers appointed to examine his experiments, draws the fullowing conclusions :

1st. That the schist of Cherbourg, when strongly calcined and pulverised, forms an excellent mortar when mixed with sciur lime.

$2 \mathrm{dly}$. That in order to give precisely the same propertics to schist which are possessed by puzzolano and terrass, the former must be calcined in a reverberating, instead of a lime, furnace.

XXVI. The Bakerian Lecture. An Account of some new anulytical Researches on the Nature of certain Bodies, particularly the Alkalies, Phosphorus, Sulphur, Carbonaceous Matter, and the Acids hitherto undecomposed; with some general Observations on Chemical Theory. By Humphry Davi, Esq., Sec. R.S., F.R.S. Eulin., and M.R.I.A.

[Concluded from p. 124.]

\section{Analytical Experiments on Muriatic Acid.}

I have made a greater number of experiments upon this substance, than upon any of the other subjects of research that have been mentioned; it will be impossible to give any more than a general view of them within the limits of the Bakerian lecture.

Researches carried on some years ago, and which are detailed in the Journals of the Royal Institution, showed that there were little hopes of decomposing muriatic acid, inlits common form, by Voltaic electricity. When aqueous solution of muriatic acid is acted upon, the water alone is decomposed; and the Voltaic electrization of the gas affords no indications of its decomposition; and merely seems to show, that this elastic fluid contains much more water than has been usually suspected.

I have alreadv laid before the Society, an account of some experiments made on the action of potassium on muriatic M 3 acid. 